\title{
Acute Liver Failure in Patients with Classic Heat Stroke
}

\author{
Jeremy J. Hernández-Ríos, ' Fátima María Martínez-González,' Luz A. Gutiérrez-Bañales, ' J. Andrés Beltrán-López, ' Hiram Jaramillo-Ramírez. ${ }^{2}$
}

\begin{abstract}
Background: Classic heat stroke is defined by a core temperature greater than $40^{\circ} \mathrm{C}$, severe dehydration and neurological alterations. Patients with liver disease due to heat stroke have been described, mostly by exercise. Hepatic failure is defined as the presence of a coagulopathy accompanied by any degree of hepatic encephalopathy. The primary objective of the study lies in the fact that patients who developed acute liver failure during their hospital stay had a higher risk of mortality. Methods: A retrospective, analytical study of patients admitted to the General Hospital of Mexicali who suffered from classic heat stroke from March 2006 through August 2010, and a second period from June 2018 to August 2019. Results: A sample of fifty patients were recruited, the group included $48(96 \%)$ male, with a total of 10 fatalities, representing $20 \%$. It was observed that parameters such as INR greater than 1.5 , aspartate aminotransferase (AST) and alanine aminotransferase (ALT) levels were not associated to an increased mortality rate. Conclusion: Neither transaminase levels, nor liver failure, were related to a higher mortality rate in this cohort of patients with classic heat stroke.
\end{abstract}

Key Words: Heat Stroke; Liver Failure; Mortality (Source: MeSH-NLM).

\section{Introduction}

Heat stroke is a severe condition that is commonly seen in countries with a warm climate. 1 There are two types: classic and exercise induced heat stroke. The classic type occurs in individuals who are exposed to high environmental temperatures without any physical activity involved. The exercise type occurs in people who are physically active in warm climates or when the ambient temperature is higher than they are adapted to or acclimatized. ${ }^{2}$ In several case reports, liver disease secondary to heat stroke have been described, mostly by exercise, with multiple outcomes like successful liver transplant, or no signs of liver function impairment. ${ }^{3}$ These patients have a core body temperature greater than $40^{\circ} \mathrm{C}$, severe dehydration and neurological disorders such as delirium, seizures or coma.4-5

Acute liver failure (ALF) is defined as the presence of coagulopathy $(I N R \geq 1.5)$ that is accompanied by any degree of hepatic encephalopathy, clinically defined by the West Haven criteria. ${ }^{6}$

The mechanism of coagulopathy development due to acute liver failure is multifactorial, consisting of decreased synthesis of procoagulant factors, anticoagulant and fibrinolytic system imbalance (mainly factors $\mathrm{V}$ and VII) and platelet dysfunction, all of this as a result of liver cell injury. ${ }^{7-8}$

Acute liver failure compromises brain metabolism by increasing cerebral flow, reducing oxygen metabolism and impairing the cerebrovascular autoregulatory mechanism. This generates neuroinflammation, which activates the microglia to produce interlukines and tumor necrosis factor-alpha (TNF- $\alpha$ ), these cause hepatic encephalopathy. ${ }^{9}$

We aim to evaluate whether patients who developed acute liver failure during their hospital stay had a higher mortality rate than those who did not present liver function impairment.

\begin{abstract}
Methods
We conducted a retrospective, analytical study of patients admitted to a secondary university Hospital in the city of Mexicali (México), who suffered from classic heat stroke from March 2006 through to August 2010, and a second period from June 2018 to August 2019. The reason there is an 8-year gap between the first and second cohort is that many patient's records were lost in a fire, the hospital only began implementing electronic files until 2015, hence the gap. The records that remained were preserved thanks to a database collected by a fellow medical resident during those years. Patients admitted to the emergency department with a diagnosis of heat stroke were included. A case of heat stroke was defined as central body temperature greater than $40 c$ c $C$, changes in alertness, and previous exposure to high environmental temperature. ${ }^{4}$ Information as sex, age, admission date, laboratory studies (blood cytometry and chemistry, liver function panel, coagulation tests), morbidities, and mortality, was collected. The highest ambient temperature according to The Weather Channel was recorded the day they were hospitalized.
\end{abstract}

Quantitative variables were expressed as mean and standard deviation (SD) or as median and interval. Student's t-test was used to compare continuous variables. The association between quantitative variables was analyzed using Spearman's correlation coefficient test.

The categorical variables were expressed as frequencies and percentages. For the comparison of proportions, the $x^{2}$ test was applied. A value of $p<0.05$ was considered statistically significant. This study was approved by Mexicali’s Ceneral Hospital Institutional Review Board.

\section{Results}

The study group included $48(96 \%)$ male. The mean age was not obtained due to a lack of information; most of the patients were homeless and usually arrived with an altered mental status that did not allow them to respond for themselves during hospitalization, many of them passed away (20\%) before being identified by a relative. Of all

\footnotetext{
2 Medical Student, Faculty of Medicine, Autonomous University of Baja California, Mexicali, B.C., México. General Hospital of Mexicali, Mexicali, B.C., México. 1 MD. Internal Medicine, Chief Professor of the Internal Medicine academic course at the General Hospital of Mexicali, México.
}

About the Author: Jeremy Hernández-Ríos is currently a 7th year medical student at the State University, Faculty of Medicine. This is his last year of a seven-year program. He is also part of a student fellowship program dedicated to community scientific research at the General Hospital of Mexicali.

Editor: Mihnea-Alexandru Căman \& Francisco Javier Bonilla-Escobar Student Editors: Madeleine Jemima Cox Submission: Nov 11, 2019

Correspondence:

Fatima Maria Martínez-González Revisions required: Nov 15, 2019; DeC 16, 2020; Feb 28, 2020

Address: Dr. Humberto Torres Sanginés S/N, Centro Cívico, 21000 Mexicali, B.C., Mexico. eived in revised form: Nov 26, 2019; Jan 15, 2020; Aug 7, 2020 Acceptance: Aug 30, 2020 Publication: Aug 31, 2020 Email: fatima.martinez@uabc.edu.mx 
patients, 19 had an INR > 1.5, with a total of 5 fatalities (OR $1.8,95 \% \mathrm{Cl}$ $0.45-7.52, p=0.2$ ) (Table 1). INR values ranged from 0.65 to 4.34 with a mean of 1.30. Spearman's correlation coefficient for INR levels and mortality was moderately positive (0.408). Eleven patients had AST levels five times greater than the normal value with a mean of $575 \mathrm{U} / \mathrm{L}$ $(p=0.175)$.

Spearman's correlation coefficient for AST levels and mortality was very low $(-0.017)$. Nine patients had ALT five times greater than the normal value (values ranged from $16-19,136 \mathrm{U} / \mathrm{L}$ ) with a mean of $559 \mathrm{U} / \mathrm{L}$ $(p=0.26)$. Spearman's correlation coefficient for ALT levels and mortality was very low $(-0.057)$ (Table 1$)$. The body core temperature recorded in patients ranged from $40{ }^{\circ} \mathrm{C}-42.5^{\circ} \mathrm{C}$ with a mean of $42{ }^{\circ} \mathrm{C}$. Finally, Spearman's correlation coefficient for body temperature and mortality was also low (-0.252). There was a $20 \%$ mortality rate.

Table 1. Relation of variables and mortality

\begin{tabular}{|c|c|c|c|c|}
\hline Variable & n (\%) & $\begin{array}{l}\text { Mortality } \\
{[n(\%)]}\end{array}$ & OR (IC 95\%) & $p$-value \\
\hline INR $>1.5$ & $19(38)$ & $5(26)$ & $1.85(0.45-7.52)$ & 0.205 \\
\hline $\begin{array}{l}\text { AST/TCO ( }>5 \text { times } \\
\text { its normal value) }\end{array}$ & $11(22)$ & $1(9)$ & $0.33(0.03-2.96)$ & 0.175 \\
\hline $\begin{array}{l}\text { ALT/TGP ( }>5 \text { times } \\
\text { its normal value) }\end{array}$ & $9(18)$ & $1(11)$ & $0.44(0.48-4.03)$ & 0.26 \\
\hline
\end{tabular}

\section{Discussion}

Several studies have reported the relationship between acute liver failure and heat stroke induced by exercise. ${ }^{1-6,10}$ Numerous case reports about exercise-induced heat stroke were analyzed, and most of them presented an increase in liver function enzymes and INR during hospitalization, meeting criteria for ALF. Giercksky et al. reported a biopsy obtained on the fifth day of hospitalization with hemorrhagic centrilobular necrosis with diffuse ballooning of the hepatocytes and moderate mixed portal and lobular inflammatory infiltrate. ${ }^{1}$ Figiel et al. analyzed five patients with ALF who met criteria for liver transplant, three of them underwent surgery and survived, maintaining close follow-up during the consecutive year without complications. One of the non-transplanted patients developed intracerebral hemorrhage, while the other patient recovered spontaneously on the fourth day. ${ }^{3}$ This is a retrospective study within a specific period, March 2006 thru August 2010, and a second period from June 2018 to August 2019, including patients with ALF due to classic heat stroke. However, the definition of acute liver failure (INR $\geq 1.5$ and encephalopathy) can be ambiguous in these patients, ${ }^{6}$ because encephalopathy is a common manifestation in patients with heat stroke.

Heat stroke is characterized as a multi-organ dysfunction; previous studies have stated that it mostly occurs in patients with multimorbidities and severe hemodynamic instability. ${ }^{11}$ In this cohort of patients, we did not find that liver dysfunction contributes to increased mortality. Davis et al. reported a case of liver failure in a patient with heat stroke induced by exercise, they considered that hypophosphatemia was a risk factor for liver damage, ${ }^{6}$ Our study could not study this particular variable due to limitations in the design.

Other authors have previously established acute liver failure's incidence at $5 \%$ in patients with heat stroke due to exercise. ${ }^{3}$ In contrast, our study demonstrated double the incidence without an increase in mortality. There is a great difference between exertional and classic heat stroke, the pre-existent physical condition of a patient who suffers from exercise induced heat stroke is not the same as the one seen at the Ceneral Hospital of Mexicali. The hospital receives a great amount of cases of classic heat stroke during summertime, therefore the staff has developed expertise on the matter, although there are not any written guidelines for management. The main strength of this study is the sample size obtained for such an uncommon disease. Nonetheless, compared to patients who suffered exertional heat stroke, our group is conformed of homeless people with an unknown history of comorbidities or previous liver damage. Classic heat stroke has a high incidence during summer in our community, further studies are necessary to evaluate the association between ALF and classic heat stroke.

There are multiple weaknesses in our work, such as including two cohorts separated in time, the absence of further workup for multiorgan failure or other causes of hepatic liver failure. However, we are at an advantage seeing that heat stroke is an uncommon disease worldwide, yet fairly common in our city, which allowed us to report its impact to liver function. 


\section{References}

1. Giercksky T, Boberg KM, Farstad IN, Halvorsen S, Schrumpf E. Severe liver failure in exertional heat stroke. Scand J Gastroenterol. 1999 Aug; 34(8):824-7.

2. Leon LR, Bouchama A. Heat stroke. Compr Physiol. 2015 Apr; 5(2):611-47.

3. Figiel W, Morawski M, Grąt M, Kornasiewicz 0, Niewiński G, Raszeja-Wyszomirska J, et al. Fulminant liver failure following a marathon: Five case reports and review of literature. World J Clin Cases. 2019 Jun; 7(12):1467-74.

4. Jaramillo-Ramírez HJ, Cota GL, Lomelí MR. Golpe de calor: un problema de salud pública en Mexicali. Salud Pública de México. 2011 Jul; 53(4):285-6. Spanish.

5. Busto Bea V, García-Alonso FJ, Moreira Vicente V. Afectación hepática en el golpe de calor. Med Clin (Barc). 2012 Apr; 138(8):361-5. Spanish.

6. Davis BC, Tillman H, Chung RT, Stravitz RT, Reddy R, Fontana RJ, et al. Heat stroke leading to acute liver injury a failure: A case series from the Acute Liver Failure Study Group. Liver Int. 2017 Apr; 37(4):509-13.
7. Munoz Santiago J, Stravitz RT, Don A. Gabriel. Coagulopathy of Acute Liver Failure. Clin Liver Dis 133. 2009 Feb;95-107.

8. Bernal William, Wendon Julia,. Acute Liver Failure. N Engl J Med. 2013 Mar; 369: 2525-34.

9. Butterworth Roger F. Pathogenesis of Hepatic Encephalopathy and Brain Edema in Acute Liver Failure. J Clin Exp Hepatol. 2014 Mar; 1-8.

10. Jin Q, Chen E, Jiang J, Lu Y. Acute Hepatic Failure as a Leading Manifestation in Exertional Heat Stroke. Case Rep Crit Care. 2012 Jun; 2012:1-4.

11. Trujillo MH, Fragachán G. C. Rhabdomyolysis and Acute Kidney Injury due to Severe Heat Stroke. Case Reports in Critical Care. 2011 Sep; 2011:1-4.

\section{Acknowledgments}

We would like to thank M.D. Alma Rosa Gastelum, for allowing us to continue researching while showing huge support towards our small scientific research group.

\section{Conflict of Interest Statement at Funding}

The Authors have no funding, financial relationships or conflicts of interest to disclose.

\section{Author Contributions}

Conceptualization: HJJR. Data Curation: LAGB. Formal Analysis: JJHR, FMMG, LAGB, JABL, HJJR. Investigation: JJHR. Methodology, Project Administration $\mathrm{A}$ Supervision: HJJR. Resources: JJHR, FMMG, LAGB, JABL. Visualization: FMMG. Writing - Original Draft Preparation: JJHR, FMMG, LAGB. Writing - Review \& Editing: JJHR C FMMG.

Cite as:

Hernández-Ríos JJ, Martínez-González FM, Gutiérrez-Bañales LA, Beltrán-López JA, Jaramillo-Ramírez HJ. Acute Liver Failure in Patients with Classic Heat Stroke. Int J Med Students. 2020 May-Aug;8(2):111-3.

This work is licensed under a Creative Commons Attribution 4.0 International License 